\title{
Commentary \\ Too Good To Be True: Second Thoughts on the Proliferation of Mental Health Courts
}

\author{
H. Archibald Kaiser \\ Schulich School of Law and Department of Psychiatry, \\ Dalhousie University
}

\section{Historical Discrimination and Criminalization}

The last two decades have witnessed the proliferation of mental health courts, proffered by governments as an efficacious and sometimes exclusive response to the complex social dynamics causing the criminalization of persons who live with mental health problems. The ready embrace of this variant of the problem-solving-courts genre has diverted policy-makers and citizens from confronting the root causes of the challenging intersection of mental illness and crime. The new courts have acquired a legitimacy that belies a wide range of doubts about their existence and operation. This commentary will offer a counterpoint to the accelerating momentum of mental health courts. It is intended to discourage their creation and to sharpen the monitoring of functioning courts.

The phenomena that spawned this novel curial option have ancient roots. Historically, people with serious mental illness have been the victims of widespread discrimination and have been relegated to the margins of society. This isolation has been accompanied by poverty, derision, coercion, institutionalization, abuse and neglect — weaving a web of social conditions that exacerbated any pre-existing vulnerability. The likelihood of incidents involving stress, decompensation, disruptive behaviour, conflict, and criminality is multiplied in such circumstances. This marginalization continues today: Persons with mental illness are "being jailed rather than helped due to the lack of community mental health services," where "the trigger for police involvement is usually a nuisance offence" (Everett et al., 2003, p. 16). Contact with the justice system frequently produces negative outcomes, unsurprising from a system that "was neither designed nor intended to address society's responsibility to the mentally disordered individual" (Schneider, Bloom, \& Heerema, 2007, p. 2). That mental health care is "one of the orphan children" or a "poor second cousin" has resulted in more law enforcement attention (e.g., Alberta's Provincial Diversion Framework, 2001, p. 4) and larger proportions of inmates of penal institutions at both the provincial and federal levels ${ }^{2}$ having mental health problems. Even proponents of mental health courts concur that "the problems we are facing within the criminal justice system would not be nearly so pressing had the civil mental health system been operating in a more potent manner" (Schneider, 2010, p. 205). This insidious situation is not unchangeable, but governments have turned too readily to mental health courts as "a pragmatic solution to the problem of untreated mental illness in the community" for accused persons who "do not really belong in the criminal justice system" (Stefan \& Winick, 2005, p. 510). 


\section{The Rush to Judgment: The Attractions of Mental Health Courts}

The "mental health court movement" (Heerema, 2005, p. 255), at times portrayed as "unstoppable" (Schneider et al., 2007, p. 217), has taken on a life of its own, notwithstanding its shaky underpinnings. Its objectives are laudable at first glance: "to remove people from the justice system" and divert them "into an environment that is more conducive to treatment"; bridge "the gap that has traditionally existed" between the criminal justice and mental health care systems; reduce "overall costs" compared to the prison setting (Heerema, 2005, p. 263); improve "public safety by reducing the recidivism rates" and enhance the "quality of life of people with mental illness" (Almquist \& Dodd, 2009, p. 2); and expedite "the assessment of the accused's fitness to stand trial" (Canadian Institute for Health Information, 2008, p. 35). These aims emerge from the broad therapeutic jurisprudence umbrella, wherein "the traditional goals of the criminal justice system" of "punishment and protection of society" are purportedly channelled to "also produce a beneficial impact on the accused," a "therapeutic conception of justice" (Schneider et al., 2007, pp. 43-44).

The targets of mental health courts have proved irresistible for jurisdictions anxious to demonstrate their responsiveness to a highly visible social problem, but these institutions are "not a panacea for addressing the needs of the growing number of people with mental illnesses who come in contact with the criminal justice system" (Bazelon Center, 2004, p. 29). They are likely not even "our best bet as a short-term fix" (Schneider et al., 2007, p. 223), despite being "conceived with the best of intentions" and being "blessed with dedicated and sensitive judges" (Stefan \& Winick, 2005, p. 511) and caring legal, clinical, and social service support staff.

\section{Ignoring or Compromising Basic Principles}

Canada's ratification of the Convention on the Rights of Persons with Disabilities ${ }^{3}$ signals a shift away from virtually exclusive reliance on the medical model, with its focus on illness, clinical discretion, mutability of the individual, and decisions made by others on the basis of best interests, toward a rights-based or disability paradigm. The key insight of the new international consensus is that "disability is not intrinsic, but rather extrinsic ... situated not in an individual pathology, but in society's failure to embrace diverse ways of being in the world" (Frazee, 2003, p. 260). Acceptance of the disability model requires society "to remove structural constraints that would enable more people to participate and gain access to social resources" (Donaghue, 2003, p. 204). The Convention should encourage a frontal assault on the amplified stigma, "the largest barrier to change in every level of the system" (Senate of Canada. Standing Committee on Social Affairs, Science and Technology, 2004, Pt. 3, Ch. 8.2.1), that surrounds persons with mental illness who are in conflict with the law and should foster a recognition of the "sanism" that "permeates mental disability law" (Perlin, 2008-09). ${ }^{4}$ Mental health courts have magnified this stigma, conveying the message that persons with mental health problems are a special population, whose threatening or disruptive behaviour requires extraordinary institutions and controls. Stefan and Winick (2005) have argued that these courts continue a segregative response to disability analogous to the "gross injustices done to African Americans by police," and that society ought not "to create a separate court system ... but to bring justice to the existing system ... however long and painful a process that may be" (p. 517). Mental health court initiatives are in need of a fundamental reassessment to ensure that Canada lives up to its international obligations by refraining "from engaging in any act or practice that is inconsistent with the present Convention" (Article 4(1)(d)) and by 
ensuring that "persons with disabilities enjoy legal capacity on an equal basis with others in all aspects of life" (Article 12(2)).

Facets of this review will be uncomfortable, requiring reflection on the "deeply entrenched attitudes and stereotypes about disability that have rendered the most flagrant abuses of the rights of persons with disabilities 'invisible' from the mainstream human rights lens"' (Melish, 2007, p. 33). Mental health courts have often been created impulsively, an expedient and visible solution to a range of "overwhelming and complex problems" (Stefan \& Winick, 2005, p. 511), but "few of the courts are part of any comprehensive plan" (Bazelon Center, 2004, p. 7). Their use is diversionary, discouraging research and investment in more propitious supports and services and creating the illusion that something positive is being done. Fundamental shortfalls are thereby ignored: "The substantial gaps in effective community services are the root of the problem and addressing them must be the first step" (Seltzer, 2005, p. 583). Some advocates recognize this deficit, noting that criminalization "will continue unless and until government is prepared to invest in a restructuring of the civil mental health care system" (Schneider et al., 2007, p. 37.) The chronic underinvestment in supports and services for people with mental illness mandates an unprecedented refocusing of spending priorities, but in the meantime, "justice systems are not the appropriate front door to access mental health care" (Seltzer, 2005, p. 583).

The momentum of mental health courts has not been slowed by another widely recognized fact: "Despite the popularity of these courts, researchers have only begun to study their processes and outcomes" (Almquist \& Dodd, 2009, p. 29), and "there is presently little empirical support for the efficacy of mental health courts" (Schneider et al., 2007, p. 217). More ominously, some scholars observe that "the results suggest that jail diversion programs, irrespective of type, have little impact on recidivism" (Sirotich, 2009, p. 470). The Canadian Institute for Health Information notes that "outcome evaluations of diversion programs are sparse" (2008, p. 34). For that matter, while recidivism is a relevant indicator of possible program success, Slinger and Roesch (2010) point to the need to attend to "other outcome variables, such as life satisfaction and psychosocial functioning," which "tended not to differ" (p. 263) between persons assigned to mental health courts and others in a treatment-as-usual group. At the very least, the paucity of evidence regarding effectiveness suggests that a moratorium on the establishment of new examples is prudent.

A curtailment of the expansionary drive of the mental health court movement may enable policy-makers to face a troubling trait of the institution, what some have called its "fundamental flaw": "Mental health courts function as a coercive agent in many ways similar to the controversial intervention of outpatient commitment" (Seltzer, 2005, p. 582), amounting to "another way to force non-dangerous people with mental illness into treatment" (Stefan \& Winick, 2005, p. 517). While purportedly universally based on "a non-coercive, voluntary system with which the defendant can choose to participate" (Slinger \& Roesch, 2010, p. 261), it is clear that the concepts of voluntariness and knowledge may be inapposite for a target population that is poor, marginalized, stressed, unstable, and stigmatized and whose only other "choice" may be to face the harshness of the conventional justice system. Researchers note that there are "indications that enrollment decisions were not knowing, intelligent, or voluntary," causing them to "question whether MHCs are as truly voluntary as intended" (Redlich, Hooper, Summers, \& Steadman, 2010, p. 101).

Beyond the dubiousness of the ostensible choice to enter the mental health court system, upon enrolment, the expectations of courts are often centred on the administration of medications, effectively silencing 
reasonable objections to their use and portraying the treatment-compliant accused as the ideal. Attention is deflected from supporting persons with mental illness to participate in society as full citizens without having to accept the ill label and the concomitant dependence on a pharmaceutical remedy. This tension is reflected in parallel developments in civil mental health law, wherein governments have a comparable enthusiasm for community treatment orders: "Aside from ... the risks to individual liberty, such initiatives give the impression that legislators are addressing the needs of patients and carers while actually doing very little at all" (Kisely, Campbell, \& Preston, 2005). Mental health courts acquire the mantle of beneficence, but they function as another source of social control without addressing foundational issues.

\section{Implementational and Procedural Problems}

The obstacles to the creation of mental health courts also provide the basis for a reevaluation of existing programs. Matters of principle are interlinked with concerns at the implementational and procedural level, which cumulatively add to the urgency of scrutinizing mental health courts more stringently.

The mere existence of mental health courts may encourage the charging of persons with mental health problems and further subjection to court processes, undermining one of the basic rationales for these courts. As Seltzer (2005) contends, "Public safety is not protected when people who have mental illnesses are needlessly arrested for nuisance crimes" (p. 582), and "half of all people with serious mental illnesses are unfairly and unnecessarily arrested" (p. 573). These objections are more salient when the arrest is premised upon a belief that "arrest will result in a superior form of mental health care" (Schneider et al., 2007, p. 218). An inherent contradiction remains when advocates simultaneously contend that many persons with mental illness do not belong in the justice system but then argue for using the same cumbersome apparatus to address the multiple issues of accused persons. Frequently, it would be better not to proceed with the charges, because "it is not the criminal justice system's function to provide mental health services" (Stefan \& Winick, 2005, p. 515).

An accused in a mental health court may experience practices that are more coercive and violative of autonomy than the sanctions to which he or she would be exposed in a regular court, which seems inconsistent with the least onerous, least intrusive, least restrictive alternative canon. Worse still, many will be subject to the authority of the court for a far longer period compared with regular offenders: "In some cases, the limits of court supervision significantly exceed the possible length of incarceration or probation for the offence" (Seltzer, 2005, p. 578). Such critical variables, involving "MHC sanctions, potential for stigma, and increased supervision, may not be well explained to potential applicants prior to court enrolment" (Redlich et al., 2010, p. 102), potentially further undermining the purported volitional aspect of participation. The Bazelon Centre (2004) suggests that the oversight period "should never exceed the typical sentence and probationary period for the underlying criminal charge," as to do so "would compound the discriminatory inequities people with mental illnesses already face" (p. 22).

Mental health court judges and other personnel may perceive themselves as part of the treatment team, an orientation that distorts conventionally assigned roles: "Judges need to focus on people's rights, not their best interests" (Stefan \& Winick, 2005, p. 522). Defenders acknowledge that "judges were never intended to be service brokers" and that "defence lawyers should be wary of cooperation," but still promote an uneasy, if "co-extensive relationship between justice and therapy" (Schneider et al., 2007, pp. 61-62). These conflicting 
ethical responsibilities and constitutional roles are not obviated merely owing to the aura of benignity of mental health court proceedings.

Additional themes, beyond the scope of this commentary, must be assessed to ensure that, prior to creating mental health courts or in managing the operation of extant courts, fundamental principles are not unduly sacrificed. Is the transfer to a mental health court and the acceptance of any court-imposed conditions truly voluntary? Is the right to withdraw from proceedings without prejudice protected? Does the accused have access to trained counsel who are dedicated to protecting his or her rights and choices? Is there a requirement of a guilty plea as a condition of participation? Is the offence with which the accused is charged within the scope of the court's policies and jurisdiction? What happens to an accused who does not comply with any conditions imposed on him or her? Does the court have any powers to ensure accountability of health care and social service providers? Are there protections against unwarranted invasions of the accused person's privacy or unjustifiable breaches of medical confidentiality? An assessment of the adequacy of any prospective response to these challenges requires both a canvassing of standards guides for mental health courts and consultation of independent experts and critics. Answers to many of these critical questions will be elusive in the absence of more rigorous research on the rationale for establishing or the efficacy of operating mental health courts. Such indeterminacy should bridle the eagerness to embark on this policy direction.

\section{Conclusion: The Need to Refocus on Other Responses to Criminalization}

Questioning the justifications for mental health courts may seem churlish to their ardent supporters. However, reducing dependence on these specialized courts is not an argument for dilution of the obligation to diminish the criminalization of persons with mental health problems. Instead, it is a call to concentrate on a sustained attack on root causes: battling stigma, discrimination, inequality, and poverty; improving conventional mental health services and complementary social supports such as housing, employment, and education programs; establishing higher standards of police responses; devising more liberal police and prosecutorial diversion policies; addressing blockages and deficiencies in services in the pre-trial setting for persons who are charged; ensuring that any necessary intrusions on liberty are minimal, sensitive, and nondiscriminatory; and demanding monitoring and accountability. ${ }^{5}$ Mental health courts have been attractive to governments that want to provide a symbolic demonstration of their resolve to control people who are seen as troublesome. Only the joint advocacy efforts of groups of persons with mental illness, families, care providers, and justice personnel will force jurisdictions to ignore the siren call of mental health courts and refocus on the tougher barriers to full participation in society faced by people with mental health problems.

\section{NOTES}

1. Commissioner Roy J. Romanow used the phrase "one of the orphan children" in his report, Building on Values: The Future of Health Care in Canada (Commission on the Future of Health Care in Canada, 2002, p. 178). The phrase "poor second cousin" comes from Michael Kirby, as cited in the Canadian Psychiatric Association Bulletin, December 2003.

2. For example, A Program Framework for Mental Health Diversion/Court Support Services (Ontario Ministry of Health and Long-Term Care, 2006 , p. 4) reported a " $27 \%$ increase in the number of people with a mental disorder who have been admitted to correctional facilities in Ontario" between 1995 and 2006. The Annual Report of the Correctional Investigator has noted this overrepresentation in successive reports since its 2004/5 observation: 


\section{CANADIAN JOURNAL OF COMMUNITY MENTAL HEALTH}

"The proportion of federal offenders with significant, identified mental health needs has more than doubled over the past decade" (p. 14).

3. U.N.G.A. A/61/661, December 2006. The Convention was signed by Canada on March 30, 2007, and ratified on March 11, 2010. See Foreign Affairs and International Trade Canada, News Release No. 368, "Government of Canada Tables Convention on Rights of Persons With Disabilities" (December 3, 2009) at http://www.international. gc.ca/media/aff/news-communiques/2009/368.aspx?lang=eng. The accompanying "Backgrounder - Convention on Rights of Persons With Disabilities" notes that "the Convention embodies an important shift toward a human dignity approach to disability and away from a charity and medical model approach" [emphasis added].

4. Michael L. Perlin (2008-09, p. 487) has developed this concept: "an irrational prejudice of the same quality and character of other irrational prejudices that cause (and are reflected in) prevailing social attitudes of racism, sexism, homophobia and ethnic bigotry."

5. Although based on conditions that are specific to the United States, the Criminal Justice/Mental Health Consensus Project report produced by the Justice Center of the Council of State Governments is a good starting point for the examination of standards for anti-criminalization initiatives (available at http://consensusproject.org/the_report).

\section{REFERENCES}

Alberta's Provincial Diversion Framework Working Committee. (2001). Reducing the criminalization of individuals with mental illness. Report submitted to the Mental Health and Justice Partnering Deputies Committee. Retrieved from http://www.albertahealthservices.ca/MentalHealthWellness/hi-mhw-ab-prov-div-reducing-crime.pdf

Almquist, L., \& Dodd, E. (2009). Mental health courts: A guide to research-informed policy and practice. New York: Council of State Governments Justice Center.

Bazelon Center for Mental Health Law. (2004). The role of mental health courts in system reform. Retrieved from http://www.bazelon.org/issues/criminalization/publications/mentalhealthcourts/

Canadian Institute for Health Information. (2008). Improving the health of Canadians: Mental health, delinquency and criminal activity. Ottawa, ON: Author. Retrieved from http://secure.cihi.ca/cihiweb/products/mh_crime_full_ report_apr11_08_e.pdf

Commission on the Future of Health Care in Canada. (2002). Building on values: The future of health care in Canada - Final report (The Romanow Report). Retrieved from http://dsp-psd.pwgsc.gc.ca/Collection/CP32-85-2002E.pdf

Donaghue, C. (2003). Challenging the authority of the medical definition of disability: An analysis of the resistance to the social constructionist paradigm. Disability and Society, 18(2), 199-208.

Everett, B., Adams, B., Johnson, J., Kurzawa, G., Quigley, M., \& Wright, M. (2003). Recovery rediscovered: Implications for the Ontario mental health system. Canadian Mental Health Association, Ontario Division. Retrieved from http://www.ontario.cmha.ca/policy_positions.asp?cID=3739

Frazee, C. (2003). Disability studies: The unexpected guest in health law discourse. Special Edition Health Law Journal, 257-262.

Heerema, M. (2005). An introduction to the mental health court movement and its status in Canada. Criminal Law Quarterly, 50, 255-282.

Kisely, S.R., Campbell, L.A., \& Preston, N. (2005). Compulsory community and involuntary outpatient community treatment for people with severe mental disorders. Cochrane Database of Systematic Reviews, Issue 10. Retrieved from http://www.mrw.interscience.wiley.com/cochrane/clsysrev/articles/CD004408/pdg_fs.htm

Melish, T. (2007). The UN Disability Convention: Historic process, strong prospects, and why the U.S. should ratify. Human Rights Brief, 14(2), 37-47.

Ontario Ministry of Health and Long-Term Care. (2006). A program framework for mental health diversion/court support services. Toronto: Queen's Printer for Ontario. Retrieved from http://www.health.gov.on.ca/english/public/pub/ ministry_reports/mentalhealth/framework.pdf

Perlin, M.L. (2008-09). 'A change is gonna come': The implications of the United Nations Convention on the Rights of Persons With Disabilities for the domestic practice of constitutional mental disability law. Northern Illinois University Law Review, 29, 483-498.

Redlich, A.D., Hooper, S., Summers, A., \& Steadman, H.J. (2010). Enrollment in mental health courts: Voluntariness, knowingness, and adjudicative competence. Law and Human Behavior, 34(2), 91-104. 
Schneider, R.D. (2010). Mental health courts and diversion programs: A global survey. International Journal of Law and Psychiatry, 33(4), 201-206.

Schneider, R.D., Bloom, H., \& Heerema, M. (2007). Mental health courts: Decriminalizing the mentally ill. Toronto, ON: Irwin Law.

Seltzer, T. (2005). Mental health courts: A misguided attempt to address the criminal justice system's unfair treatment of people with mental illnesses. Psychology, Public Policy, and Law, 11(4), 570-586.

Senate of Canada. Standing Committee on Social Affairs, Science and Technology. (2004). Mental health, mental illness and addiction: Overview of policies and programs in Canada. Report 1. Interim report of the Standing Committee chaired by Hon. M.J.L. Kirby and deputy chair Hon. W.J. Keon. Retrieved from http://www.parl. gc.ca/38/1/parlbus/commbus/senate/com-e/soci-e/rep-e/report1/repintnov04vol1-e.pdf

Sirotich, F. (2009). The criminal justice outcomes of jail diversion programs for persons with mental illness: A review of the evidence. Journal of the American Academy of Psychiatry and the Law, 37(4), 461-472.

Slinger, E., \& Roesch, R. (2010). Problem-solving courts in Canada: A review and a call for empirically-based evaluation methods. International Journal of Law and Psychiatry, 33(4), 258-264.

Stefan, S., \& Winick, B.J. (2005). Foreword: A dialogue on mental health courts. Psychology, Public Policy, and Law, $11(4), 507-526$. 